\title{
Solidification Processing of Te-Sb-Pb Alloys For Thermoelectric Applications
}

\author{
T. Ikeda*, H. Azizgolshani**, S. M. Haile*, G. J. Snyder** and V. A Ravi** \\ *Materials Science, California Institute of Technology \\ **Jet Propulsion Laboratory/California Institute of Technology
}

\begin{abstract}
A solidification processing approach to the refinement of lead-tellurium-antimony alloy microstructure is described. Liquid alloys with eutectic, hyper-eutectic and hypo-eutectic compositions (relative to lead) were cooled to the solid state in three distinct ways, i.e. by water quenching, air cooling and furnace cooling. The structures of the alloys resulting from the three different solidification paths were examined using electron microscopy and the micrographs were quantified. Classical solidification methods were used to interpret the structures in relation to the cooling histories.
\end{abstract}

\section{Keywords}

Tellurium-antimony-lead, solidification, dendrite structure, secondary dendrite arm spacing, lamella structure

\section{Introduction}

The development of efficient thermoelectric devices for both space and terrestrial applications requires the discovery of materials with a high thermoelectric figure of merit, zT, defined as $S^{2} \sigma T / \kappa$, where $S$ is the Seebeck coefficient, $\sigma$ the electrical conductivity and $\kappa$ the thermal conductivity. Materials investigated and optimized over the past 50 years have been conventional, simple semiconductors. Examples include bismuth telluride alloys, lead telluride alloys and silicon germanium alloys. Here we examined a system of two immiscible thermoelectric materials: $\mathrm{PbTe}_{-} \mathrm{Sb}_{2} \mathrm{Te}_{3}$. While the phase diagram of this psuedo-binary system is in dispute, the literature agrees that a moderately deep eutectic occurs at approximately $40 \mathrm{~mol} \% \mathrm{PbTe}$ with a melting temperature of approximately $585^{\circ} \mathrm{C}$. Such a feature suggests that under the right synthesis conditions, the material will exhibit a nanoscale lamellar structure composed of the two thermoelectric end-member compounds. Ideally, such structures can result in quantum confinement effects, increasing $\mathrm{S}$, and/or in enhanced phonon scattering, decreasing $\kappa$.

Traditional approaches to thermoelectric fabrication are based on a powder metallurgical route. One of the key advantages of the $\mathrm{P} / \mathrm{M}$ route is the homogeneity in the final microstructure; however, this method offers very little opportunity for structural refinement unless the raw materials, i.e., the powders themselves are engineered to have the desired shape and size. Liquid-solid transformations offer the opportunity to significantly alter the final microstructure by controlling the cooling history of the material. In addition, considerable advantages can be achieved by altering the composition of the alloy around the ternary eutectic composition, i.e., $40 \mathrm{~mol} \%$ (PbTe)-60 mol\% $\left(\mathrm{Sb}_{2} \mathrm{Te}_{3}\right)$.

The specific objectives of the present study were to refine the microstructure by altering solidification rates and to investigate the effect of alloy composition.

\section{Experimental procedure}

Elemental $\mathrm{Pb}, \mathrm{Sb}$ and Te granules or powders (99.999\% purity) were sealed in quartz tubes $10 \mathrm{~mm}$ in diameter under vacuum. The compositions of the alloys were chosen to be $21.7 \mathrm{~mol} \%$ (PbTe)-78.3 mol\% $\left(\mathrm{Sb}_{2} \mathrm{Te}_{3}\right)(\mathrm{Te}-36$ at.\% $\mathrm{Sb}-5$ at. $\% \mathrm{~Pb}), 40 \mathrm{~mol} \%$ (PbTe)-60 mol\% $\left(\mathrm{Sb}_{2} \mathrm{Te}_{3}\right)(\mathrm{Te}-31.5$ at.\% $\mathrm{Sb}-10.5$ at. $\% \mathrm{~Pb}$ ) and $62.5 \mathrm{~mol} \%$ (PbTe)-37.5 $\mathrm{mol} \%$ $\left(\mathrm{Sb}_{2} \mathrm{Te}_{3}\right)(\mathrm{Te}-24$ at.\% $\mathrm{Sb}-20$ at.\% $\mathrm{Pb})$, all of which can be located on the psuedo-binary $\mathrm{PbTe}-\mathrm{Sb}_{2} \mathrm{Te}_{3}$ phase diagram. For notational ease, the $\mathrm{Sb}_{2} \mathrm{Te}_{3}$ content is hereafter omitted. The alloys were then melted by induction heating and were held at temperatures above $924^{\circ} \mathrm{C}$ for approximately 5 minutes and then were solidified at three different cooling rates, i. e. by water quenching and air cooling.

(a)

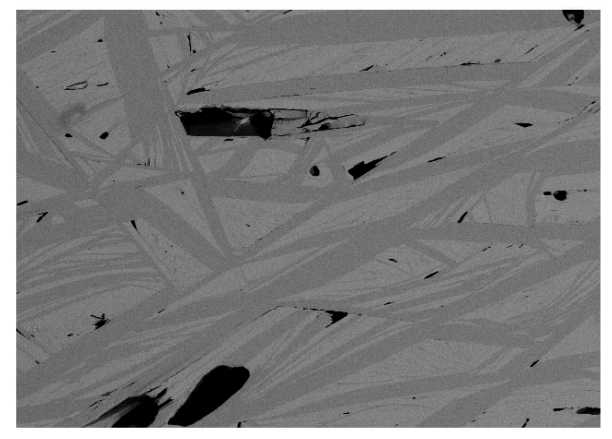

(b)

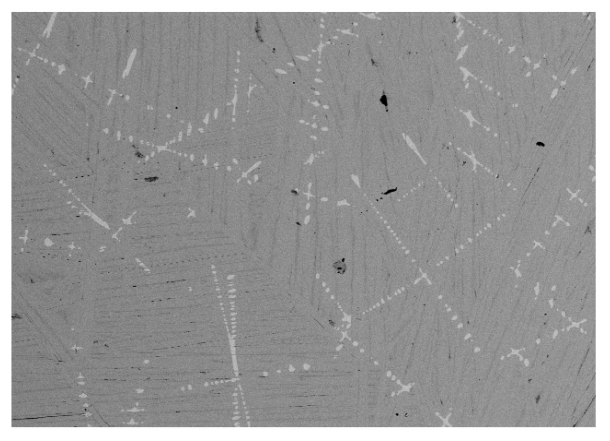

(c)

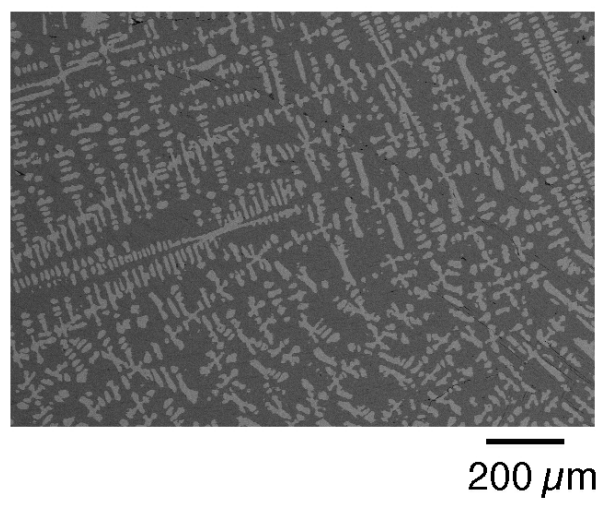

Figure 1: Microstructure of Te-Sb-Pb alloys solidified by air cooling. The compositions are $21.7 \mathrm{~mol} \%(\mathrm{PbTe})(\mathrm{a}), 40$ $\mathrm{mol} \%(\mathrm{PbTe})(\mathrm{b})$ and $62.5 \mathrm{~mol} \%(\mathrm{PbTe})(\mathrm{c})$, respectively. 
The alloys thus prepared were cut, mounted in epoxy pucks and polished finally with $0.3 \mu \mathrm{m} \mathrm{Al}_{2} \mathrm{O}_{3}$ paste. The microstructures were observed using a field emissionscanning electron microscope (Carl Zeiss LEO 1550 VP) equipped with a Robinson backscattered electron (BSE) detector for its high compositional contrast capabilities. The microstructures were analyzed using a personal computer with an image processing program (Macscope, Mitani Corp.) for quantitative description. The compositions of constituent phases in each alloy were measured using an energy dispersion X-ray spectrometry (EDS, INCAEnergy energy dispersion X-ray microanalysis system, Oxford Instruments).

(a)

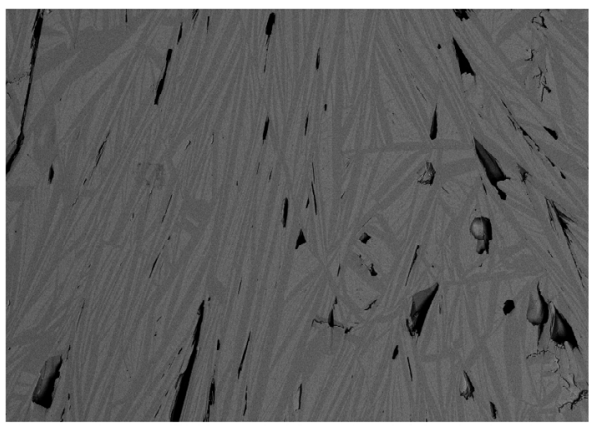

(b)

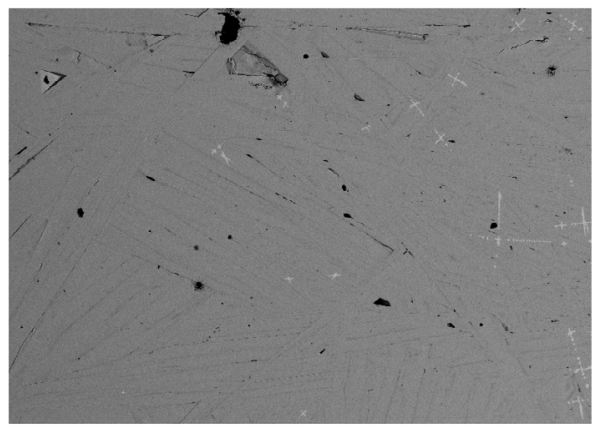

(c)

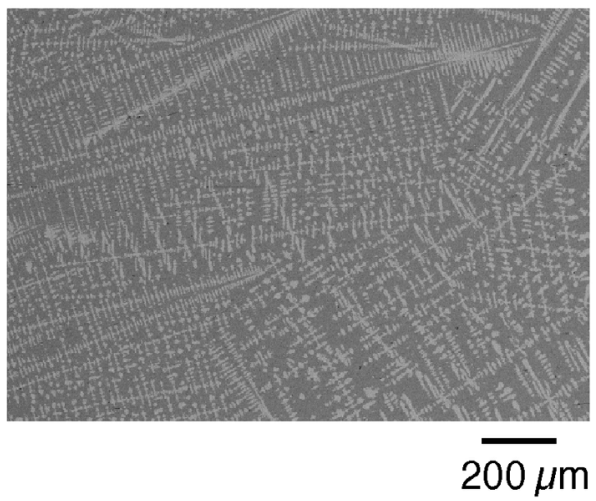

Figure 2: Microstructure of Te-Sb-Pb alloys solidified by water quenching. The comositions are $21.7 \mathrm{~mol} \%$ (PbTe) (a), $40 \mathrm{~mol} \%$ (PbTe) (b) and $62.5 \mathrm{~mol} \%$ (PbTe) (c), respectively.

\section{Microstructural morphology and phase assemblage}

Figures 1 and 2 show the backscattered electron image of microstructures in the alloys solidified by air cooling and water quenching, respectively. Lamellar structures are observed in the alloy with the composition of $21.7 \mathrm{~mol} \%$ $(\mathrm{PbTe})$ regardless of cooling rates. On the other hand, the $62.5 \mathrm{~mol} \%(\mathrm{PbTe})$ alloy has a dendrite structure, and the 40 $\mathrm{mol} \%(\mathrm{PbTe})$ alloy, which has a composition near the eutectic composition, is composed of a gray matrix phase, light dendritic features and dark lamellar phases.

Composition analyses using EDS in the present work showed that the matrix phase in all alloy compositions investigated are near $\mathrm{Pb}_{2} \mathrm{Sb}_{6} \mathrm{Te}_{11}$. The dark lamellar phase in $21.7 \mathrm{~mol} \%(\mathrm{PbTe})$ is $\mathrm{Sb}_{2} \mathrm{Te}_{3}$. The dendrites in $62.5 \mathrm{~mol} \%$ (PbTe) and $40 \mathrm{~mol} \%$ (PbTe) alloys are $\mathrm{PbTe}$. The existance of an intermediate phase of composition $\mathrm{Pb}_{2} \mathrm{Sb}_{6} \mathrm{Te}_{11}$ has been proposed by Abrikosov, On the other hand, recently, Shelimova et al. [2] suggested, on the basis of X-ray diffraction experiments, that $\mathrm{PbSb}_{4} \mathrm{Te}_{7}$ and $\mathrm{PbSb}_{2} \mathrm{Te}_{4}$ phases can be present rather than $\mathrm{Pb}_{2} \mathrm{Sb}_{6} \mathrm{Te}_{11}$. The current results are consistent with the phase diagram presented by the former authors, Fig. 3. We attribute the lamellar microstructure of the eutectic and $\mathrm{Sb}$ rich alloys to the layered crystalline structures of the constituent phases, $\mathrm{Pb}_{2} \mathrm{Sb}_{6} \mathrm{Te}_{11}$ and $\mathrm{Sb}_{2} \mathrm{Te}_{3}[2,3]$. In contrast, $\mathrm{PbTe}$ has a cubic structure (rocksalt type) [4].

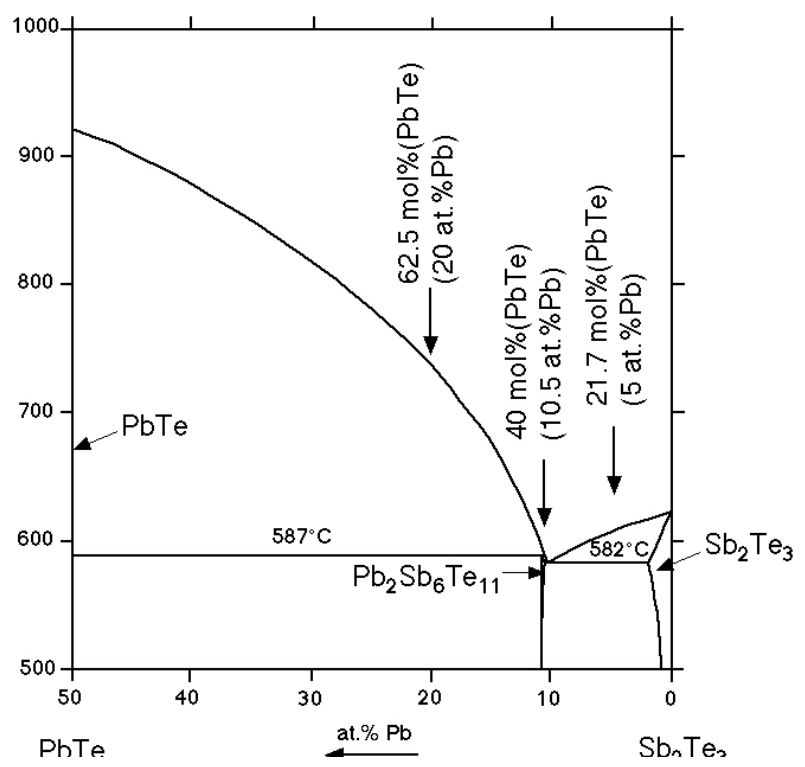

Figure 3: Equilibrium phase diagram of the psuedo-binary $\mathrm{PbTe}_{\mathrm{Sb}} \mathrm{Te}_{3}$ system [1].

Figure 4 (a) shows the fraction of dendrite in the 62.5 $\mathrm{mol} \%(\mathrm{PbTe})$ alloy, which was determined by image analyses. The fraction of dendrite is found to be around $26 \%$ regardless of cooling rate and to agree with the fraction of PbTe phase expected from the equilibrium phase diagram proposed by Abrikosov [1].

For the $21.7 \mathrm{~mol} \%$ (PbTe) alloy, solidification was also performed by furnace cooling. The fraction of lamella in this alloy slightly decreases with increasing cooling rate as shown in Fig. 4 (b). In the figure, the fraction of $\mathrm{Sb}_{2} \mathrm{Te}_{3}$ phase expected from the equilibrium phase diagram is indicated by broken lines. Since lead is slightly soluble in the $\mathrm{Sb}_{2} \mathrm{Te}_{3}$ phase and the solubility varies with temperature, the fraction of the $\mathrm{Sb}_{2} \mathrm{Te}_{3}$ phase in solidified alloys can be expected to vary with cooling rate; the upper bound corresponds to the maximum solubility of lead and the lower limit to zero solubility, respectively. The experimental fraction is found to lie within 
this range. Therefore, the fraction of lamella experimentally observed is also consistent with the equilibrium phase diagram proposed by Abrikosov.

\section{Secondary dendrite arm spacing}

For the 62.5 and $40 \mathrm{~mol} \%$ (PbTe) alloys, the secondary dendrite arm spacing (SDAS) was determined by image analysis. There is no significant difference between the SDAS near the perimeter and at the center of the ingot samples (data not shown). This is attributed to the fact that the thermal conductivity of the quartz container ( $1.5 \mathrm{~mm}$ thick) [5] is roughly comparable to that of the Te-Sb-Pb alloys $[6,7]$. Thus, the resulting cooling rate of the alloy adjacent to the container wall (usually the highest in permanent mold castings) is reduced. Therefore, the temperature gradient within the alloys is expected to be small. This can lear similar cooling rates near the perimeter and at the center.
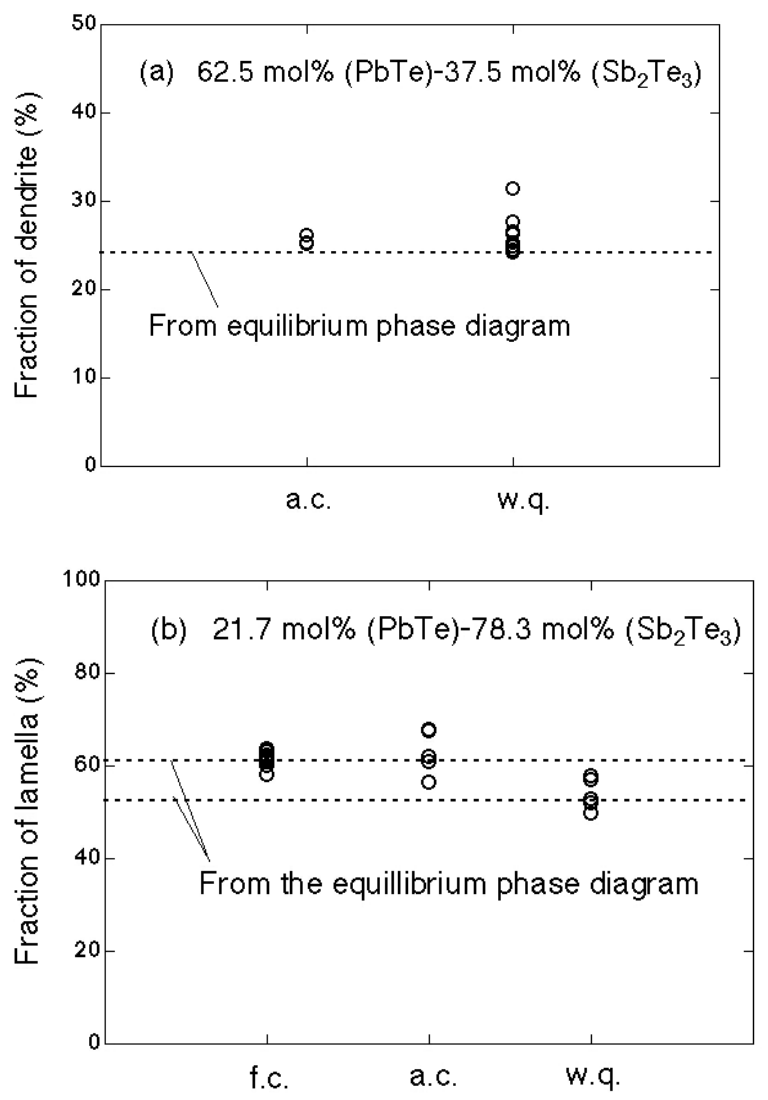

Figure 4: Fraction of dendrite in the $62.5 \mathrm{~mol} \%$ (PbTe)- alloy (a) and lamella in the $21.7 \mathrm{~mol} \%$ (PbTe) alloy (b). The broken lines show the fraction expected from the equilibrium phase diagram [1]. The upper line is calculated from the solibility limit of $\mathrm{Pb}$ in $\mathrm{Sb}_{2} \mathrm{Te}_{3}$ and lower line to zero solubility in $\mathrm{Sb}_{2} \mathrm{Te}_{3}$.

It is clearly apparent from Figs 1 and 2 that the water quenched samples have finer microstructure than the air cooled samples. Figures 5 and 6 show the histograms of the SDAS obtained by the image analyses for the 40 and 62.5 $\mathrm{mol} \%$ (PbTe) alloys, respectively. The SDAS in the water quenched samples are significantly smaller than that in the air cooled ones; the average SADS in the water quenched 40 mol\% (PbTe) sample is $10.9 \mu \mathrm{m}$ whereas that in the air cooled sample is $21.1 \mu \mathrm{m}$, Fig. 5, with a similar trend evident for the $62.5 \mathrm{~mol} \%$ (PbTe) alloy, Fig. 6. This result reflects the higher cooling rate of water quenching than air cooling.
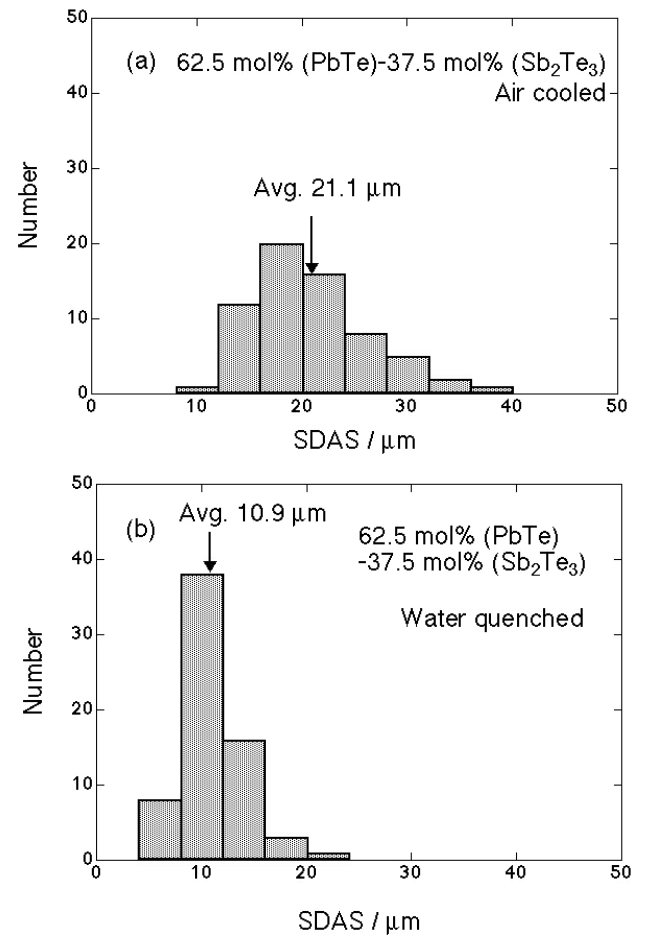

Figure 5: Distribution of secondary dendrite arm spacings observed in $62.5 \mathrm{~mol} \%$ (PbTe) alloys solidified by air cooling (a) and water quenching (b).
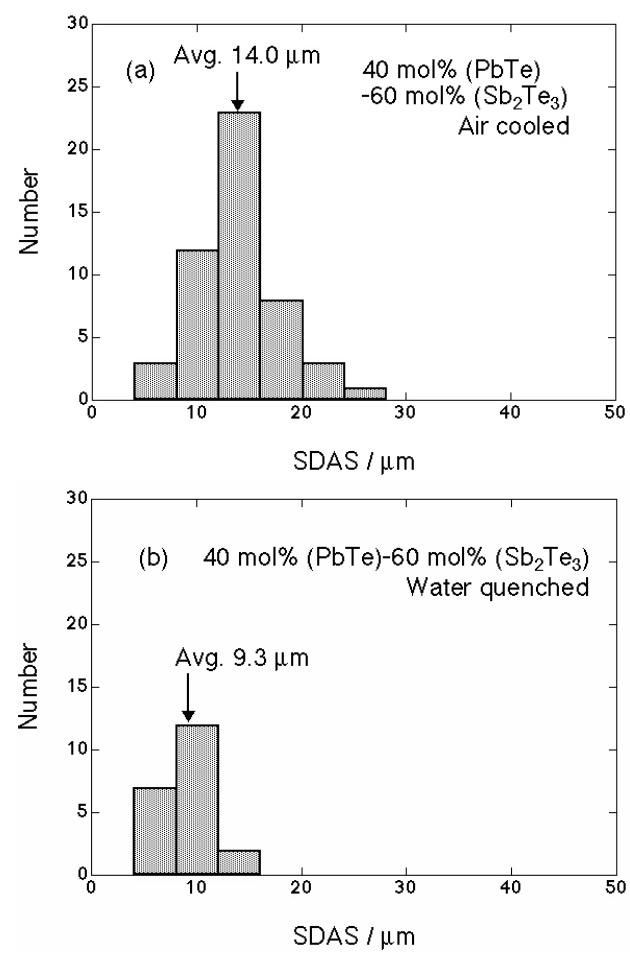

Figure 6: Distribution of secondary dendrite arm spacings observed in $40 \mathrm{~mol} \%$ (PbTe) alloys solidified by air cooling (a) and water quenching (b). 


\section{Inter-lamellar spacing}

For the $21.7 \mathrm{~mol} \%$ (PbTe) alloy, inter-lamellar spacing was determined by image analyses on the microstructures. Figure 7 shows the distribution of lamella spacing for air cooling and water quenching. The average separation between lamellae is smaller for the water quenched samples in comparison to the air cooled ones. Thus, it is found that the inter-lamellar spacing can also be controlled by changing solidification rates.
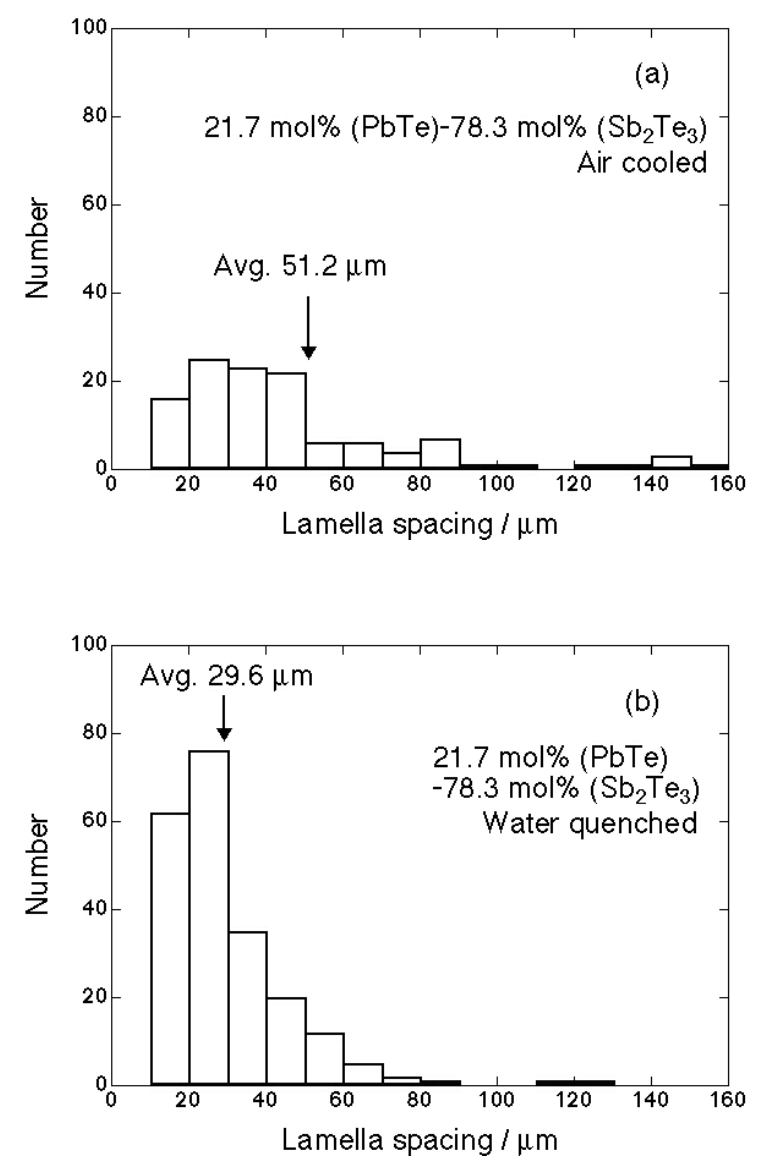

Figure 7: Distribution of lamella thickness observed in 21.7 mol\% (PbTe) alloys solidified by air cooling (a) and water quenching (b).

\section{Conclusions}

The microstructure transitions from lamellar to dendritic as the fraction of PbTe increases from $21.7 \mathrm{~mol} \%$ to $62.5 \%$. It is to be noted that the $\mathrm{Pb}_{2} \mathrm{Sb}_{6} \mathrm{Te}_{11}$ phase appears to be present in all microstructures.

Water quenched samples have finer microstructures compared to air cooled ones. This includes the decrease in the interlamellar spacing for the $\mathrm{Sb}_{2} \mathrm{Te}_{3}$-rich alloys $(21.7 \mathrm{~mol} \%$ (PbTe)-78.3 mol\% $\left(\mathrm{Sb}_{2} \mathrm{Te}_{3}\right)$ ) and decrease in SDAS for the PbTe-rich alloys (40 mol\% (PbTe)-60 mol\% $\left(\mathrm{Sb}_{2} \mathrm{Te}_{3}\right)$ and $62.5 \mathrm{~mol} \%$ (PbTe)-37.5 mol\% $\left.\left(\mathrm{Sb}_{2} \mathrm{Te}_{3}\right)\right)$ when the materials are water quenched. Thus, the characteristic microstructural lengthscales were found to be tunable by changing the cooling rate during solidification. More rapid cooling can be expected to produce nanoscale structural features, which is desirable for enhancing the thermoelectric figure of merit.

\section{Acknowledgments}

TI is supported by NSF through Caltech's Center for the Science and Engineering of Materials (CSEM). Portions of this work were carried out at the Jet Propulsion Laboratory/California Institute of Technology; $\mathrm{HA}$ is supported by the JPLUS program at JPL/Caltech. We gratefully acknowledge the assistance of Dr. Chi Ma of Caltech for assistance with electron microscope image acquisition.

\section{References}

1 Abrikosov, N. Kh. et al., "The system $\mathrm{Pb}-\mathrm{Sb}_{2} \mathrm{Te}_{3}$," Inorganic matter., Vol. 1 (1965), pp. 1944-1946.

2 Shelimova et al., "Synthesis and Structure of Layered Compounds in the $\mathrm{PbTe}-\mathrm{Bi}_{2} \mathrm{Te}_{3}$ and $\mathrm{PbTe}_{2} \mathrm{Sb}_{2} \mathrm{Te}_{3}$ Systems," Inorganic matter., Vol. 40 (2004), pp. 14401447.

3 Belotskii, D. P. et al., "Crystal structure and electrical properties of alloys the system $\mathrm{In}_{2} \mathrm{Se}_{3}-\mathrm{Sb}_{2} \mathrm{Te}_{3}$," Inorganic matter., Vol. 8 (1972), pp. 1677-1681.

4 Noda, Y. et al., "Temperature dependence of atomic thermal parameters of lead chalcogenides, $\mathrm{PbS}, \mathrm{PbSe}$ and PbTe," Acta crystallographica, Vol. 43C (1987), pp. $1443-$ 1445 .

5 Thermophisical Properties of High Temperature Solid Materials, Vol. 4: Oxide and their solutions and mixtures, Part 2, ed. Touloukian, Y. S., The Macmillan Company (New York, 1967), pp. 1657-1658.

6 Lost'ák, P. et al., "Preparation and some physical properties of tetradymite-type $\mathrm{Sb}_{2} \mathrm{Te}_{3}$ single crystals doped with CdS," J. cryst. growth, Vol. 222 (2001), pp. 565-573.

7 Yoneda, S. et al., "Crystal grain size dependence of thermoelectric properties for sintered $\mathrm{PbTe}$ by spark plasma sintering technique," $16^{\text {th }}$ International Conference on Thermoelectrics, Dresden, Germany, Aug. 1997, pp. 247-250. 